$\left[\begin{array}{l}\text { 街 } \\ \text { EISEI } \text { KAGAKU } \\ 31(6) 377-384(1985)\end{array}\right]$

\title{
Direct Detection of Glutathione S-Transferase on a Gel Plate by Treatment with Glutathione and 1-Chloro-2, 4-dinitrobenzene
}

\author{
Hideo Isono and Shuich Mryaura \\ Faculty of Pharmaceutical Sciences, Teikyo University, Sagamikomachi, \\ Tsukui-gun, Kanagarwa 199-01, Japan
}

(Received June 4, 1985)

\begin{abstract}
A method was developed to directly detect glutathione S-transferase (GST) on the surface of a gel-plate after electrophoresis. First, a photograph of the background photoabsorption of the gelplate was taken by exposing photographic paper laid under the gel-plate to ultraviolet light ( $365 \mathrm{~nm})$ without any chemical treatment of the gel surface. Next, the same plate was evenly coated with a solution consisting of $3 \mathrm{ml}$ of $20 \mathrm{~mm}$ reduced glutathione (GSH) in water and $0.3 \mathrm{ml}$ of $30 \mathrm{~mm}$ 1-chloro-2,4-dinitrobenzene ( $C D N B)$ in ethanol. This plate was observed under ultraviolet light $(365 \mathrm{~nm})$, and photoabsorbing spots were directly photographed by the same method as before. Finally, the same plate was stained with Coomassie Brilliant Blue R-250 to give a protein picture. The mutual comparison of these three electrophoretic pictures made it possible to detect GSTs despite the presence of many other proteins on the gel-plate.
\end{abstract}

Keywords-glutathione S-transferase; glutathione; 1-chloro-2,4-dinitrobenzene; electrophoresis; glutathione S-transferase direct detection

\section{Introduction}

Glutathione S-transferases ${ }^{1)}$ are present in many organisms, including plants ${ }^{2-5)}$ and insects suchas the $f l y,{ }^{6,7)}$ cockroach $^{8)}$ and mothlarva. ${ }^{9)}$ Therefore, a method for monitoring these enzymes is desirable to establish their distribution, and to evaluate the capacity of each tissue for glutathione-conjugation. On the other hand, analysis of these enzyme forms ${ }^{10)}$ is also important for characterizing the activities of the enzymes toward individual substrates. Their form sare chromatographically separable from each other by employing such adsorbents as DEAE- and CM-cellulose, Sephadex, hydroxyapatite, etc. The final confirmation of the enzyme purity is generally performed by electrophoresis. However, there remains a question as to whether the stained protein band(s) has activity for glutathioneconjugate formation. Thus, a direct method for detecting these enzymes is required. A few direct methods using methyliodide, glutathione and hydroperoxide ${ }^{11)}$ or using iodine, 1-chloro2,4-dinitrobenzene and glutathione ${ }^{12)}$ have already been reported, but in the present study, we developed a much simpler method using 1-chloro-2,4-dinitrobenzene (CDNB) and glutathione (GSH) under ultraviolet light for detecting these enzymes on the surface of a gel-plate after electrophoresis. This method was applied to tissue samples from rat, mouse and rabbit. The cockroach was also tested because this insect is expected to contain glutathione S-transferase( $\mathrm{s}$ ) involved in the detoxication of such pesticides as Sumithion and Malathion.

\section{Experimental}

Reagents and Apparatus-1) Agar: Agar Noble; Difco Laboratories.

2) Reduced Glutathione (GSH) and 1-Chloro- 
2,4-dinitrobenzene (CDNB): special grade, Wako Pure Chemical Industries Ltd.

3) Dyestuff: Coomassie Brilliant Blue R-250; Nakarai Chemical Ltd.

4) Developer and Fixing Solution: 10-fold dilute Korectol and Fujifix, Fuji Photo Film Co, Ltd.

5) Photographic Paper for Printing: Mitsubishi Hishicopy, type $\mathrm{CH}, 80 \mathrm{~g} / \mathrm{m}^{2}$, high sensitivity and high contrast grade, Mitsubishi Paper Mills Ltd.

6) Standard Rat Liver Glutathione S-Transferases (GST): Ligandin, activity toward CDNB, $3.4 \mu \mathrm{mol} / \mathrm{min} / \mathrm{ml}$; GST-B, $3.1 \mu \mathrm{mol} / \mathrm{min} / \mathrm{ml}$; GST. $\mathrm{C}_{2}-3,3.3 \mu \mathrm{mol} / \mathrm{min} / \mathrm{ml}$; GST.Peak II, $2.8 \mu \mathrm{mol} /$ $\mathrm{min} / \mathrm{ml}$. The first three standards, ${ }^{13)}$ obtained from the flow-through fraction on a DEAE-cellulose column ( $\mathrm{pH} 8.0,10 \mathrm{~mm}$ Tris-HCl buffer) were chromatographically purified on CM-cellulose and hydroxyapatite columns. The last one, ${ }^{14)}$ derived from the DEAE-bound fraction, was chromatographically purified on DEAE-cellulose, Sephadex and hydroxyapatite columns. These prepared standards were confirmed to be homogenous on polyacrylamide-gel electrophoresis.

7) DE-23 and CM-52 Cellulose: Whatman Chemical Separstion Ltd.

8) Cellulose Tubing: $36 / 32$ inch for dialysis, Union Carbide Co.

9) Voltage Stabilizer: type SJ-1061, Atto Co.

10) Ultraviolet Lamp: Manaslu-Light, main wavelength $365 \mathrm{~nm}$, Manaslu Chemical Industry Ltd.

11) Double-Beam Spectrophotometer: Hitachi model $100-60$.

Preparation of Tissue Sample Solutions for Electrophoresis — Mouse: Three four-week-old male DDY strain mice, average body weight $24 \mathrm{~g}$, were sacrificed by decapitation. The following organs were excised and rinsed in ice-cold water. Excess water was removed with blotting paper. The same organs from the three mice were combined and weighed. Each type of organ was homogenized in three volumes of water using a Teflon-glass homogenizer, and the homogenate was filtered through a paper (Toyo Roshi No. 101.)
The filtrate was subjected to agar-gel electrophoresis.

Organs: liver; kidney; lung; spleen; intestine from duodenum to colon; heart; brain; seminal vesicle with contents; combined testis, caput epididymis and cauda epididymis; and eyeball with contents.

Rat: A male Wistar strain rat weighing $420 \mathrm{~g}$, more than six months old, was treated as described above to afford homogenates $(1: 3, w / v)$ of the following organs: liver; kidney; lung; spleen; intestine from duodenum to colon; cecum; stomach; heart; brain; seminal vesicle with contents; caput epididymis; testis; cauda epididymis.

Rabbit: A male Japanese Ordinal White strain rabbit weighing $2.45 \mathrm{~kg}$ was killed by injecting air into the ear vein. The following organs were treated as described above to afford homogenates ( $1: 3, \mathrm{w} / \mathrm{v})$ : liver; kidney; adrenal; spleen; lung; heart; bladder; colon; appendix; cecum; ileum; duodenum and jejunum; stomach; brain; caput epididymis; testis; cauda epididymis; eyeball with contents.

Cockroach: Blattella germanica L., average body weight $100 \mathrm{mg}$, was killed by freezing for more than $1 \mathrm{~h}$ at $-20^{\circ} \mathrm{C}$.

a) Whole Body Homogenate: A mixture of whole bodies of several cockroaches, irrespective of sex, was homogenized in three volumes of ice-cold water using a Teflon-glass homogenizer. The homogenate was passed through a plug of cotton-wool and subjected to electrophoresis.

b) Digestive Organ: This part was obtained by pulling the head from the body. The transparent tube-like organ was collected and homogenized in water to give a homogenate $(1: 3, \mathrm{w} / \mathrm{v})$.

c) Abdominal Contents: After removing the digestive organ, the white mucous content of the abdomen was collected by pressing the abdomen. This was treated in water to give a homogenate ( $1: 3$, $w / v)$.

d) Embryo: The light greenish mucous content of the embryo vesicle was collected by pressing the vesicle. This was treated to give a homogenate $(1: 3, \mathrm{w} / \mathrm{v})$. 
Preparation of CM-52 Chromatographic Fractions for Electrophoresis-A female Japanese Ordinal White strain rabbit ${ }^{15)}$ weighing $3.8 \mathrm{~kg}$ was sacrificed by bleeding. A portion $(50 \mathrm{~g})$ of the liver $(99 \mathrm{~g})$ was homogenized in five volumes of water and centrifuged at $20000 \times g$ for $60 \mathrm{~min}$ at $4^{\circ} \mathrm{C}$. The supernatant $(254 \mathrm{ml})$ was applied to a DE-23 cellulose column $(4 \times 40 \mathrm{~cm})$, previously equilibrated with $10 \mathrm{mM}$ Tris-HCl buffer $(\mathrm{pH} 8.0)$. The column was washed with the same buffer. Fractions ( $19 \mathrm{ml} /$ tube) were collected and monitored for glutathione S-transferase activity toward 1-chloro2,4-dinitrobenzene (CDNB). Active fractions were combined $(517 \mathrm{ml})$ and concentrated to a few $\mathrm{ml}$ by dialysis against polyethylene glycol-6000 for $15 \mathrm{~h}$ at $4^{\circ} \mathrm{C}$ in cellophane tubing (36/32 inch). The concentrated solution was successively dialyzed against 4 changes, each of 21 , of $10 \mathrm{~mm}$ potassium phosphate buffer ( $\mathrm{pH} 6.7$ ) for $2,2,2$ and $15 \mathrm{~h}$ at $4^{\circ} \mathrm{C}$. The resultant solution $(50 \mathrm{ml})$ was centrifuged at $20000 \times g$ for $20 \mathrm{~min}$ to remove floating materials. All of this solution was applied to a CM-52 cellulose column $(1.9 \times 20 \mathrm{~cm})^{10)}$ previously equilibrated with $10 \mathrm{~mm}$ potassium phosphate buffer $(\mathrm{pH} 6.7)$. The column was washed with the same buffer until the initial active peak had been eluted. After 26 fractions had been collected ( $10 \mathrm{ml} /$ tube), beginning with the sample application, the column was eluted with a $\mathrm{KCl}$ linear gradient prepared from $500 \mathrm{ml}$ of $10 \mathrm{~m} M$ potassium phosphate buffer, $\mathrm{pH} \mathrm{6.7,} \mathrm{in}$ the mixing chamber and $500 \mathrm{ml}$ of $60 \mathrm{mM} \mathrm{KCl} \mathrm{in}$ the same buffer in the reservoir. The fractions (10 $\mathrm{ml} /$ tube) obtained were subjected to analytical agar-gel electrophoresis.

Measurement of Glutathione S-Transferase Activity toward CDNB-Sample solution, 20$200 \mu 1$, was mixed with $2 \mathrm{ml}$ of $1.5 \mathrm{~mm}$ reduced glutathione in $0.1 \mathrm{M}$ potassium phosphate buffer $(\mathrm{pH}$ 6.5) and $100 \mu 1$ of $30 \mathrm{mM} \mathrm{CDNB}$ in ethanol. The mixture was adjusted to a final volume of $3 \mathrm{ml}$ with the above buffer and shaken for $5 \mathrm{~s}$ at $25^{\circ} \mathrm{C}$ on a vibrator. The photoabsorbances at $340 \mathrm{~nm}$ were read at 30 and $60 \mathrm{~s}$ by using a $1 \mathrm{~cm}$ light path cell in a double-beam spectrophotometer. The activity toward $\mathrm{CDNB}, \mu \mathrm{mol}$ of CDNB-glutathione. conjugate formed $/ \mathrm{min} / \mathrm{ml}$ of sample solution, was calculated by means of the following equation: activity $=3000 \cdot \Delta E /(\Delta \varepsilon \cdot \mathrm{t}(\mathrm{min}) \cdot$ sample solution $(\mathrm{ml}))$. where $\Delta E$ is the initial increase in photoabsorbance during $\mathrm{t} \min$ and $\Delta \varepsilon=9600 \cdot \mathrm{M}^{-1} \cdot \mathrm{cm}^{-1}$ is the difference in molar extinction coefficient at $340 \mathrm{~nm}$ between $\mathrm{CDNB}$ and its glutathione conjugate.

Agar Gel Electrophoresis-1) Preparation of Agar Gel Plates: Agar Noble and $\beta$-alanine, 0.25 $\mathrm{mg}$ each, were dissolved in $50 \mathrm{ml}$ of water by boiling, and $0.5 \mathrm{ml}$ of $0.5 \mathrm{~N} \mathrm{KOH}$ was immediately added with vigorous stirring. All the gel solution was rapidly poured onto a glass plate $(19 \times 19 \mathrm{~cm}$, $1 \mathrm{~mm}$ thick), all the edges of which were embanked by sticking slender glass plates ( $5 \mathrm{~mm}$ in width, $1 \mathrm{~mm}$ thick) around the edges of a $20 \times 20$ cm glass plate with a silicone paste (KE-45, Shinetsu Kagaku). This prepared gel plate was left standing for more than 4 or $5 \mathrm{~d}$ at $4{ }^{\circ} \mathrm{C}$ in a closed. vessel, and then used for electrophoresis. The completed plate showed a $\mathrm{pH}$ of about 8.5. Around the center of the plate, several circular wells were made ( $1-4 \mathrm{~mm}$ diameter), and $2-8 \mu \mathrm{l}$ of sample: solution was placed in the wells by using a microsyringe. The plate was horizontally bridged over both electrode solutions ( $200 \mathrm{ml}$ of $0.1 \mathrm{~N} \mathrm{KOH}$, for both) through a filter paper (Toyo Roshi, No. 2).

2) Conditions of Electrophoresis: Electrophoresis was done at a constant voltage of $100 \mathrm{~V}$ regulated on a stabilizer (type SJ-1061, Atto Corporation) for $2-5 \mathrm{~h}$ at room temperature. The current decreased from about 5 to $1 \mathrm{~mA}$ during electrophoresis.

3) Gel Staining for Protein: After electrophoresis, the gel plate was stained with $0.0025 \%$. Coomassie Brilliant Blue R-250 dissolved in a solvent mixture of methanol, acetic acid and water $(5: 1: 4, \mathrm{v} / \mathrm{v} / \mathrm{v})$.

Direct Detection of Glutathione S-Transferase on the Surface of the Gel-Plate after Electrophoresis - The electrophoresed plate was. immediately photographed by the method described. below to give photograph-A (background). Then photograph-B was obtained by the same method. after chemical treatment of the same plate. Photo- 
graph-C was finally obtained by staining the same plate with Coomassie Brilliant Blue R-250 followed by conventional photograpy.

Chemical Treatment: A mixture of two solutions, i.e., $3 \mathrm{ml}$ of $20 \mathrm{~mm}$ reduced glutathione (GSH) in water and $0.3 \mathrm{ml}$ of $30 \mathrm{~mm} \mathrm{1-chloro-2,4-dinitro-}$ benzene (CDNB), was rapidly poured onto the surface of a gel plate. The gel surface was evenly coated with this reagent by rolling a glass rod $(5 \mathrm{~cm}$ long, $1 \mathrm{~cm}$ i.d.) on the plate. The coated plate was left standing for more than several minutes at room temperature until photoabsorbing spots appeared under an ultraviolet light (365 $\mathrm{nm}$ ). It is important that the above two reagent solutions are mixed just before use and applied immediately.

Photographic Method: A gel-plate was laid on top of a photographic paper, and then directly exposed for less than $1 \mathrm{~s}$ to an ultraviolet light $(365 \mathrm{~nm})$ set at a position of approximately 1 meter above the gel-plate. The exposed paper was conventionally developed and fixed to give the best picture by checking the degree of development under a red safe-light.

\section{Results}

\section{Electrophoresis of Rat Liver Standard Glu-} tathione S-Transferase

Fig. 1-A showed the photoabsorbing picture of a gel-plate immediately after electrophoresis of rat liver standard GST and other control samples. This intact gel-plate did not show any photoabsorbing spot. However, as shown in Fig. 1-B, the chemical treatment of the same plate, with CDNB and GSH, gave a clear photoabsorbing spot for each GST standard. These spots were superimposable on protein spots (Fig. 1-C) visualized by staining the same plate. The photoabsorbing spot in each lane of the GST standards in Fig. 1-B is due to glutathione conjugate of CDNB enzymatically formed by GST. Therefore, by elimination of the background spots in Fig. 1-A from those in Fig. 1-B, it is possible to identify the spots GST(s) which are present among other proteins in Fig. 1-C. If both Fig. 1-A and $1-B$ give a photoabsorbing spot at the same position, it will be difficult to judge whether or not the photoabsorbing spot in Fig. 1-B reflects the enzymatic formation of a CDNB-GSH conjugate. However, this problem can be overcome by prior removal of intrinsic photoabsorbing materials from the sample through chromatography, e.g., on Sephadex.

\section{Electrophoresis of Chromatographic Frac- tion Samples}

As shown in Fig. 2 (Graph), CM-52 column chromatography of rabbit liver yielded clear peaks of GST activity and protein content. Each fraction was subjected to agar-gel electrophoresis and the plate was directly photographed under an ultraviolet light (Fig. 2-A). This intact gelplate did not show any photoabsorbing spot. However, the same plate treated with $\mathrm{CDNB}$ and GSH (Fig. 2-B) gave clear photoabsorbing spots. The intensity of the photoabsorbing spots roughly paralleled the GST activity shown in the graph. This method was found to have high sensitivity: 3 $\mu l$ of an eluate fraction (between fractione No. 76 and 82 ), possessing an activity of $2 \mu \mathrm{mol} /$ $\mathrm{min} / \mathrm{ml}$, yielded a clear photoabsorbing spot. Figure. 2-C showed the protein pattern. The protein coinciding with the photoabsorbing spots (Fig. 2-B) is considered to contain GST active toward CDNB.

Electrophoresis of Male Rat Tissue Samples

Fig. 3-A shows the gel plate just after the electrophoresis of whole homogenates of male rat organs. This plate did not show any photo absorbing spot. The same plate (Fig. 3-B) after treatment with $\mathrm{CDNB}$ and GSH showed several photoabsorbing spots for most organs between standard GST-B and GST-Peak II. The testis showed the second most intense spots (after the liver), and at least five spots 


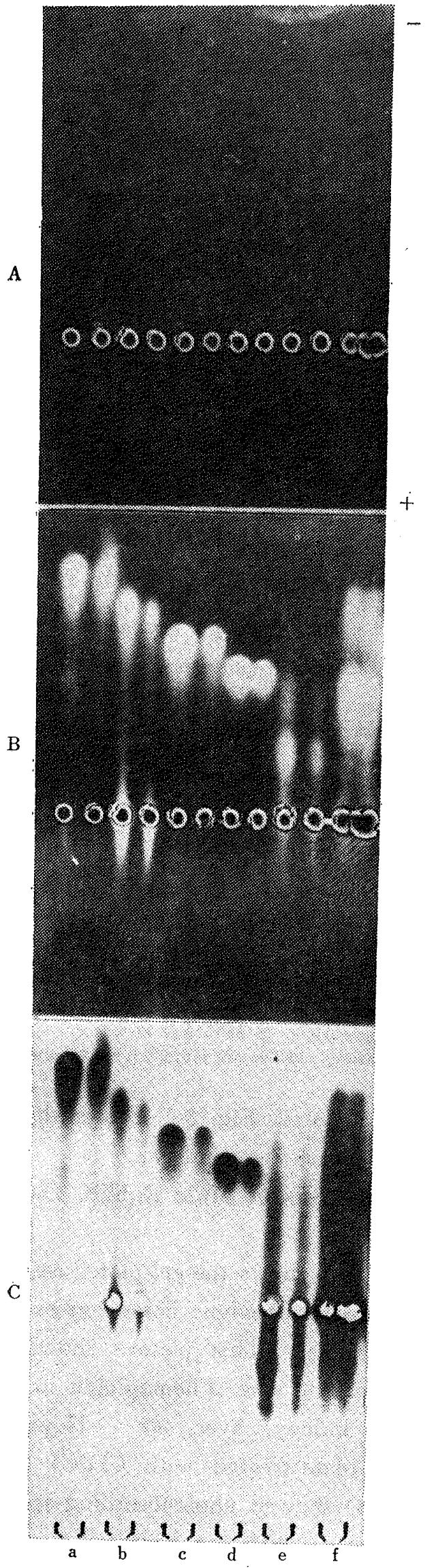

Fig. 1. Electrophoretic Patterns of Rat Liver Standard GST

A : Intact gel-plate after electrophoresis. B : The plate treated with CDNB and GSH. C: The plate stained with coomassie brilliant blue R-250.

a) GST-Ligandin, b) GST-B. c) GST- $\mathrm{C}_{2}-3$.

d) GST-Peak II. e) rat testis whole homogenate.

f) rat liver whole homogenate.

Homogenates $: 1: 3, w / \nabla$ in water.

Pairs of samples : 5 and $2.5 \mu \mathrm{l}$.

Conditions : $11 \mathrm{~d}$ stored plate, $5.5 \mathrm{~h}$ electrophoresis.

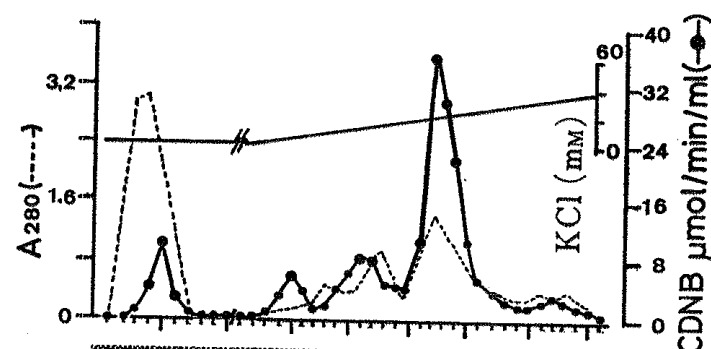

A

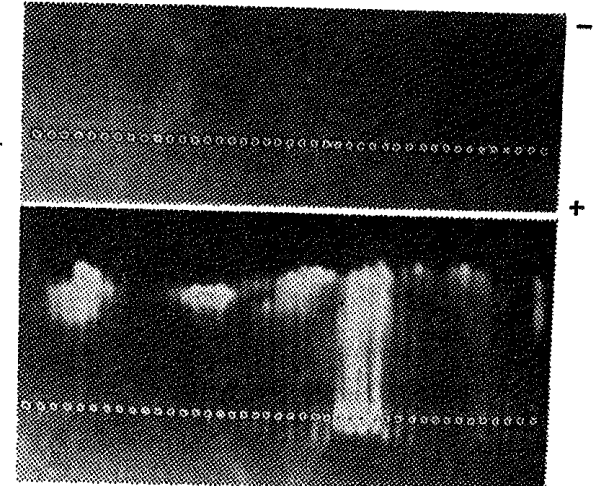

$\mathrm{C}$

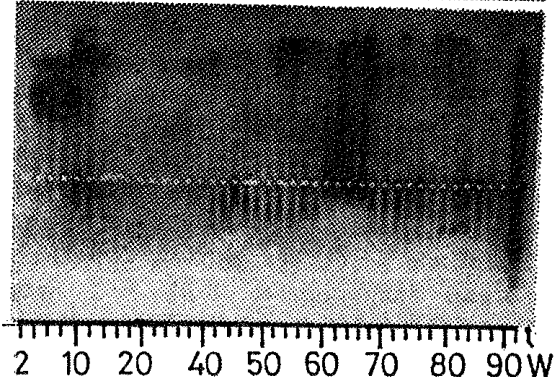

Fig. 2. Electrophoretic Patterns of Column Chromatographic Fractions of $\mathrm{Fe}$ male Rabbit Liver GST

Graph : Profiles of GST activity toward CDNB and of protein in eluates from a CM-cellulose column. Numbers are fraction numbers. Sample size for electrophoresis, $3 \mu 1$ of each $10 \mathrm{ml}$ fraction.

A : Intact gel-plate aftr electrophoresis. B: The plate treated with CDNB and GSH. C: The plate stained with coomassie brilliant blue R-250.

w) female rabbit liver whole homogenate, $1 \mu 1$, $1: 6, \mathrm{w} / \mathrm{v}$ in water.

Conditions : $13 \mathrm{~d}$ stored plate, $3 \mathrm{~h}$ electrophoresis. 

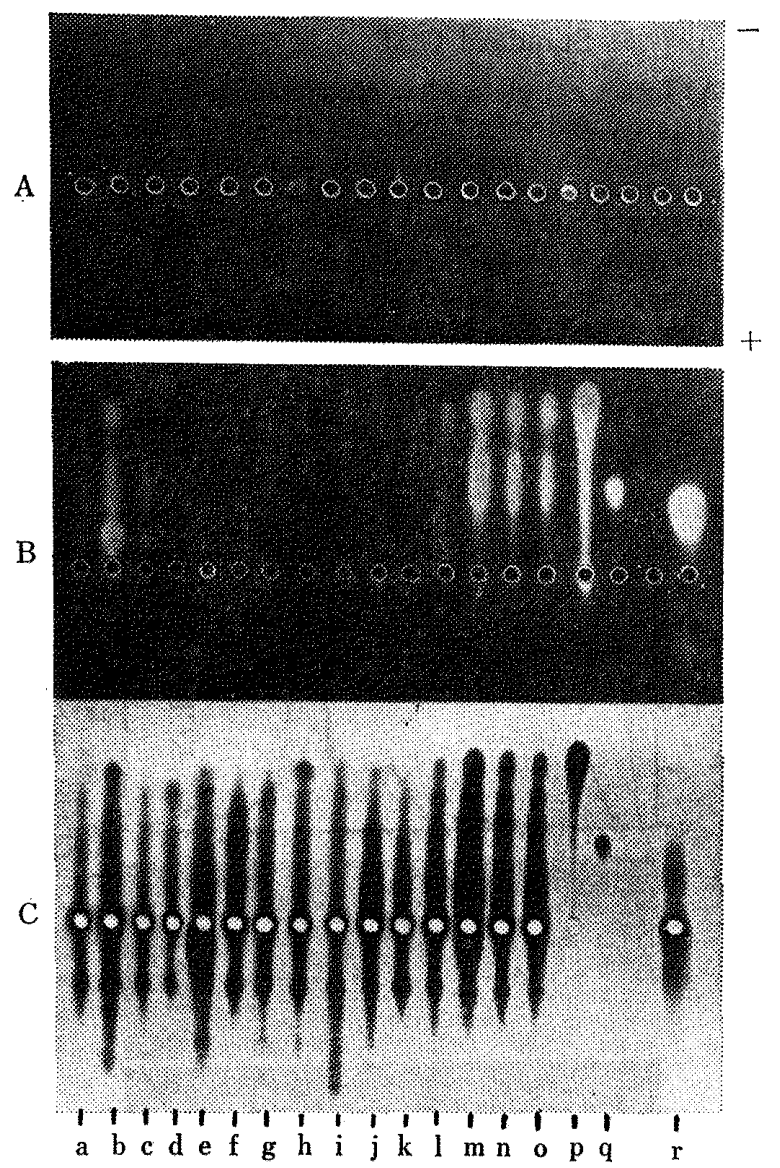

Fig. 3. Electrophoretic Patterns of Male Rat Tissue Samples

A : Intact gel-plate after electrophoresis. B : The plate treated with CDNB and GSH. C:The plate stained with coomassie brilliant blue R-250.

a) cauda epididymis. b) testis. c) caput epididymis. d) seminal vesicle with contents.

e) brain. f) heart. g) stomach. h) cecum. i) duodenum, jejunum, ileum, colon and rectum. j) spleen. k) lung. 1) kidney. $m, n$ and $o$ ) liver, $5,2.5$ and $1.5 \mu 1$, respectivly. Rat tissues: whole organ homogenate, $5 \mu 1,1: 3, w / v$ in water. p) GST-B, $2 \mu 1$. Q) GST-Peak II, $1 \mu 1$. r) cockroach whole body homogenate, $5 \mu 1,1: 3$, $w / v$ in water.

Conditions : $5 \mathrm{~d}$ stored plate, $3 \mathrm{~h}$ electrophoresis.

were resolved. The spots from the caput epididymis and cauda epididymis were relatively faint, but the profiles were similar to that of the testis. These three generative organs each showed a main photoabsorbing spot, which was less mobile than that of the cockroach. This result suggested that the testis, caput epididymis and cauda epididymis each contain a characteristic GST(s) having a relatively low
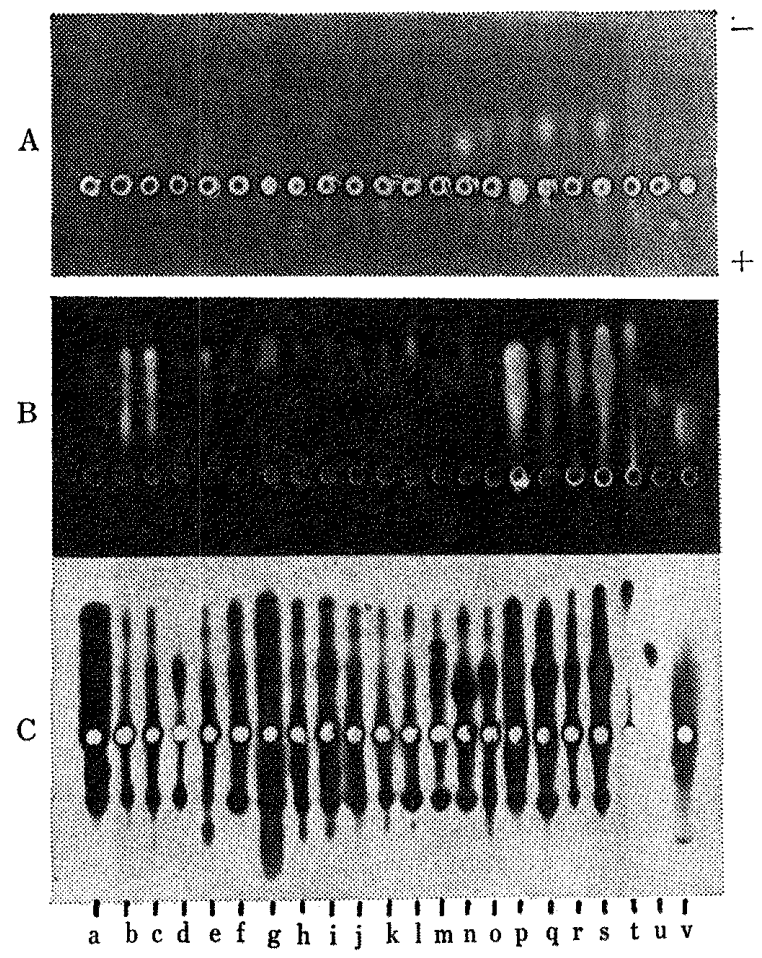

Fig. 4. Electrophoretic Patterns of Male Rabbit Tissue Samples

A : Intact gel-plate after electrophoresis. B : The plate treated with CDNB and GSH. C: The plate stained with coomassie brilliant blue $\mathrm{R}-250$.

a) eyeball with contents. b) cauda epididymis.

c) testis. d) caput epididymis. e) brain.

f) stomach. g) duodenum and jejunum. h) ileum.

i) cecum. j) appendix. k) colon. 1) bladder.

m) heart. n) lung. o) spleen. D) adrenal.

q) kidney. $r$ and s) liver, 2 and $5 \mu 1$, respectively. Rabbit tissues: whole organ homogenate, $5 \mu 1,1: 3, w / v$ in water. t) GST-B, $1 \mu 1$. u) GST-Peak II, $1 \mu \mathrm{l}$. v) cockroach whole body homogenate, $5 \mu 1,1: 3, \mathrm{w} / \mathrm{v}$ in water.

Conditions : $16 \mathrm{~d}$ stored plate, $2 \mathrm{~h}$ electrophoresis.

isoelectric point. Fig. 3-C shows the protein pattern in each tissue of rat.

\section{Electrophoresis of Male Rabbit Tissue Samples}

Fig. 4-A shows the gel-plate just after the electrophoresis of whole homogenates of male rabbit organs. This picture shows a clear photoabsorbing spot of hemoglobin in the lanes of lung, kidney, liver, etc. However, the same gel-plate treated with CDNB and GSH (Fig. 4-B) showed photoabsorbing spot (s) for all samples in different regions on the plate. The adrenal gave a more intense spot than 
the liver. This suggested that rabbit adrenal contains a high level of GST. The testis and epididymis each gave three intense spots, among which the least mobile spot appeared near the position of that from the cockroach. Thus, the generative organs appeared to contain at least three GSTs at high concentration. Figure. 4-C shows the protein pattern in each sample.

\section{Electrophoresis of Male Mouse Tissue and Cockroach Samples}

Figure. 5-A showed the gel-plate just after the electrophoresis of male mouse and cockroach samples. This picture shows a photoabsorbing spot of hemoglobin in the lanes of liver, kidney, lung, hoart, etc. However, the same plate treated with CDNB and GSH (Fig. 5 -B) gave other photoabsorbing spots for each mouse sample. Testis and seminal vesicle (including contents) were found to have GST at high concentrations, though the liver had the highest concentration. GST in the testis could be resolved into at least three spots. Every cockroach sample (whole body, digestive organ, abdominal white contents and embryo) gave one clear photoabsorbing spot near the position of the least mobile among the three spots of mouse testis (Fig. 5-B). This result suggested that mouse testis and cockroach each contain a characteristic GST(s) having a relatively low isoelctric point. Fig. 5-C showed the protein pattern in each sample.

\section{Discussion}

We developed a direct method for detecting GST on the surface of a gel-plate after electrophoresis, based on the observation of a UV-photoabsorbing spot of CDNB-GSH conjugate formed by GST. This approach is reasonable because 1) CDNB-GSH conjugate should be formed at the location of GST on the plate in the presence of CDNB, 2) UV. light (approximately $365 \mathrm{~nm}$ ) is more effec-

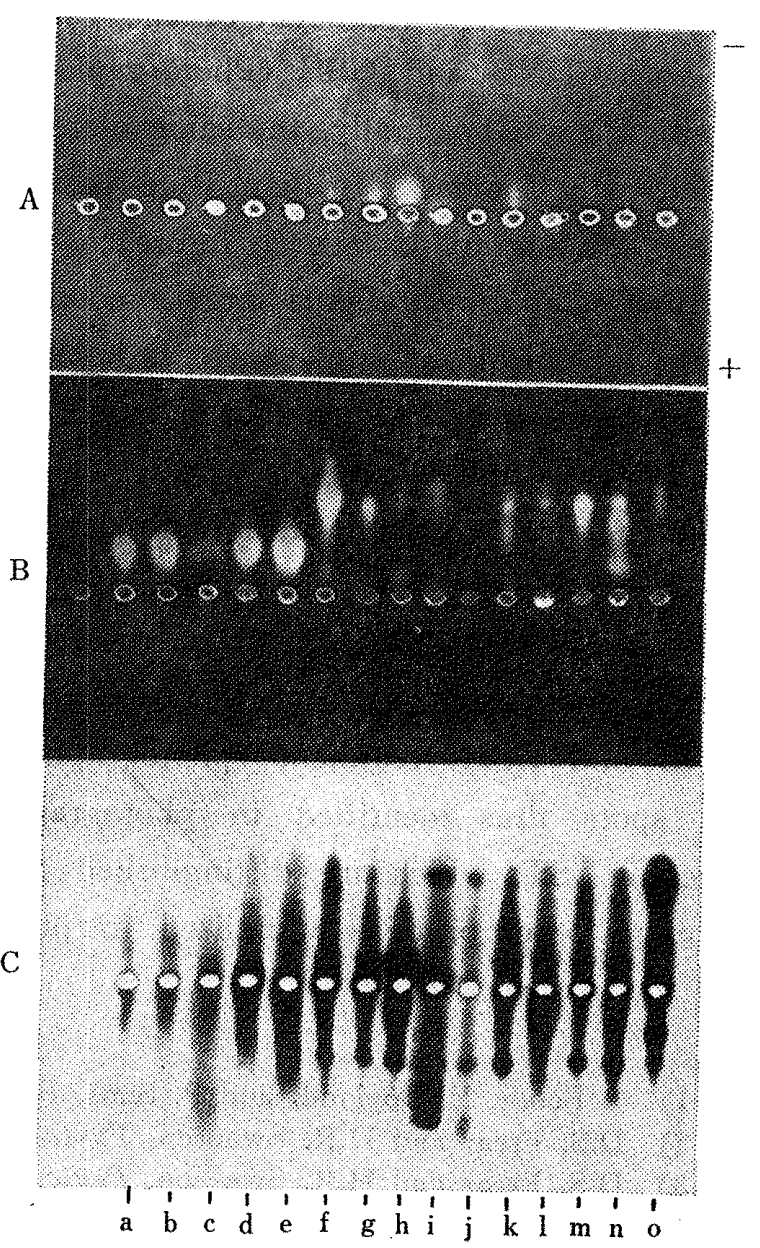

Fig. 5. Electrophoretic Patterns of Male Mouse Tissue Samples and Cockroach Samples

A: Intact gel-plate after electrophoresis. B: The plate treated with CDNB and GSh. C : The plate stained with goomassie brilliant blue R-250.

$a$ and b) cockroach whole body, 2.5 and $5.0 \mu$ l respectively. c) digestive organ. d) abdominal white contents. e) embryo. Gockroach samples: whole homogenate, $5 \mu 1,1: 3, \mathrm{w} / \mathrm{v}$ in water. f) mouse liver. g) kidney. h) lung. i) spleen. j) stomach, duodenum, jejunum, ileum, cecum, colon and rectum, k) heart. 1) brain. m) seminal vesicle with contents. $n$ ) testis. 0 ) eyeball with contents. Mouse tissues: Whole organ homogenate, $5 \mu 1, \mathrm{w} / \mathrm{v}$ in water.

Conditions : $7 \mathrm{~d}$ stored plate, $2 \mathrm{~h}$ electrophoresis.

tively absorbed by CDNB-GSH conjugate than by CDNB, 3) every GST currently known acts on $\mathrm{CDNB}$ as a substrate.

The present method involves the following three steps. I) The gel-plate immediately after electrophoresis was photographed to obtain a background picture (Photograph-A in each figure). II) The same plate was photographed 
again after chemical treatment of the gel-surface with CDNB and GSH (Photograph-B in each figure). III) Finally, the same plate was stained with Coomassie Brilliant Blue R-250 for protein (Photograph-C in each figure).

If a sample contains a large amount of colored biological material, such as hemoglobin, myoglobin, bile pigment or bilirubin, this material gave photoabsorbing spot(s) in spite of the chemical treatment of the gel-plate with CDNB and GSH. Such spots could be eliminated by subtracting those in the background picture (photograph-A) from those seen after CDNB and GSH treatment (photograph-B). The spots thus identified in photograph-B represent GSTs which are distinguished from the many other proteins visualized in photo-
graph-C. If excessive amounts of materials giving photoabsorbing spots in photograph-A are present, they can be removed by chromatography, e.g., on Sephadex, before electrophoresis of the samples.

Cockroach $^{8)}$ (Blattella germanica L.), and the testis ${ }^{16)}$ (and epididymis ${ }^{17)}$ ) of mouse, rat and rabbit were all found to have characteristic GSTs. Their isoelectric points seem to be relatively low compared with those of standard GSTs: GST-Ligandin (pI, ca. 9.4), GST-B (ca. 9.0), GST-C ${ }_{2}-3(7.7-8.0)$, GST. Peak II (ca. 7.4).

This direct method of electrophoretic detection of GSTs by using CDNB and GSH should be very useful for monitoring ${ }^{18)}$ of the enzyme, detection of inhibitors of GSTs, etc.

\section{References}

1) J. Booth, E. Boyland, and P. Sims, Biochem. J., 79, 516 (1961).

2) D.S. Frear and H.R. Swanson, Phytochemistry, 9, 2123 (1970).

3) D.S. Frear and H.R. Swanson, Pestic. Biochem. Physiol., 3, 473 (1973).

4) M.B. Guddewar and W.C. Dauterman, Phytochemistry, 18, 735 (1979).

5) T.J. Mozer, D.C. Tiemeier, and E.G. Jaworski, Biochemistry, 22, 1068 (1983).

6) N. Motoyama and W.C. Dauterman, Comp. Biochem. Physiol, 63B, 451 (1979).

7) J.A. Otte and F.W. Plapp. Jr., Pestic. Biochem. Physiol., 22, 203 (1984).

8) K. Usui, J. Fukami, and T. Shishido, Pestic. Biochem. Physiol., 7, 249 (1977).

9) A.G. Clark and B. Drake, Biochem, J., 217, 41 (1984).

10) W.H. Habig, M.J. Pabst, and W.B. Jakoby, J. Biol. Chem., 249, 7130 (1974).

11) A.G. Clark, Anal. Biochem., 123, 147 (1982).

12) R.C. Strange, P.H. Hirrell, G.A. Kitley, D.A. Hopkinson, and W. Cotton, Biochem. J., 215,213 (1983).

13). S. Miyaura, T. Kubota, and H. Isono, Chem. Pharm. Bull., 32, 3134 (1984).

14) T. Kubota, S. Miyaura, and H. Isono, Chem. Pharm. Bull., 33, 2044 (1985).

15) K.R. Gawai and S.S. Pawar, Xenobiotica, 14, 605 (1984).

16) C. Guthenberg, I.M. Åstrand, P. Ålin, and B. Mannervik, Acta. Chem. Scand. Ser., B. 37,261 (1983).

17) D.J. Meyer, L.G. Christodoulides, K.H. Tan, and B. Ketterer, FEBS Lett., 173, 327 (1984).

18) H. Isono and S. Miyaura, Eisei Kagaku, 30, 363 (1984). 